\title{
Evaluation of Regional Science and Technology Innovation Policy Effect Based on Lasso and BP Neural Network
}

\author{
Zhang Yongan and Guan Yongjuan
}

\begin{abstract}
Regional science and technology innovation policies have important strategic significance for China to build an innovative country. Scientific and objective evaluation of the effects of science and technology innovation policies is the main problem to be solved at present. In this context, this paper takes Beijing as an example to evaluate the effects of scientific and technological innovation policies by using lasso and BP neural network algorithms. The empirical results show that supply-driven policies have obvious effects, and the effects show an upward trend year by year, while the environmental policies have a significant decline, and the demand-driven policies still have much room for improvement. Finally, the next research direction is proposed.
\end{abstract}

Index Terms-Scientific and technological innovation, policy effects, BP neural network, Lasso.

\section{INTRODUCTION}

On May 20, 2016, the State Council issued the outline of the national strategy for innovation-driven development, proposing to build China into a world power in science, technology and innovation, and a major science center and innovation plateau by 2050 . Technological innovation is once again the focus of the industry. As a programmatic document to promote the development of scientific and technological innovation, scientific and technological innovation policy has also become a hot topic for scholars to study. In recent years, in order to realize the great goal of becoming a strong country in science and technology, a number of scientific and technological innovation policies have been launched from the national level to the local level. Therefore, whether these scientific and technological innovation policies can achieve the expected effect is still worth in-depth discussion. This paper evaluates the effects of science and technology innovation policies by using relevant data of Beijing's science and technology innovation policies, and determines which policies have obvious effects and which policies need to be improved and adjusted, which is of great significance for determining the direction, adjustment and termination of relevant policies.

At present, the effect evaluation of scientific and technological innovation policy has become the focus of

Manuscript received August 12, 2019; revised October 2, 2019.

Y. Zhang and Y. Guan are with the College of Economic and Management, Beijing University of Technology, 100022 China (Corresponding Author: Y. Guan; e-mail: bjutzhya@bjut.edu.cn; 875749156@qq.com). public policy research at home and abroad. Domestic scholars have made many achievements in the research on policy effect evaluation, but most of them take the policy type as the starting point of the evaluation. Gui Huangbao, by constructing spatial econometric model for China's government procurement, promoted scientific evaluation of the effect of technology innovation policy [1]. Chen Ling and Yang Wenhui analyzed allocation mechanism of R\&D tax deduction policy and policy effect [2]. Liu Huizhen the carbon tax policy based on grey relation analysis to our country industrial enterprise technology innovation behavior performance influence [3]. Some scholars, also according to different industry science and technology innovation policy to do in-depth study effect, Zhu Minghao using factor analysis, entropy weight method and gray comprehensive evaluation method of empirical study on effect of China's automobile industry technology innovation policy [4]. Li Fengmei et al. explored the impact of industrial policies on the innovation performance of photovoltaic enterprises and economic performance under different market and policy environments [5]. Li Zibiao et al. studied the effect of innovation policies on high-tech enterprises by using multi-layer linear model [6]. Also have domestic scholars in a specific area do policy study effect evaluation of the breakthrough point, this part of the research is mainly combined with different provinces and regions to do effect of regional technology innovation policy research, throughout the domestic scholar's research, in the innovation policy effect evaluation methods used in the present diversity, method of DEA, grey correlation degree, the fuzzy mathematics theory, office value method, expert scoring method, econometric model and analytic hierarchy process, factor analysis, set pair analysis method, least squares estimation and Heckman two step correction method, but there are few scholars combined with big policy effect evaluation on the data analysis method, This paper tries to find a new perspective of policy effect evaluation.

The contributions of this paper are mainly reflected in the following two aspects: first, this paper enriched the research on the effects of existing scientific and technological innovation policies through the big data analysis method -BP neural network algorithm. Since the existing literature rarely USES big data analysis method to evaluate the effect of science and technology innovation policy, this paper attempts to use BP neural network algorithm to evaluate the effect of science and technology innovation policy. Secondly, this paper studies the effects of science and technology innovation policies from a new perspective. Existing literatures mostly focus on specific policy studies and studies 
in a certain region. This paper attempts to analyze the policy effects of different types of policies. In conclusion, based on the existing research, this paper explores the policy effects of supply-driven, demand-driven and environment-driven policies through Lasso and BP neural network algorithm.

\section{METHODS AND RESULTS}

In September 2016, The State Council issued a notice on Beijing's overall plan to strengthen the construction of national science and technology innovation center. As a national science and technology innovation center, Beijing not only drives the economic development of Beijing, TianJin and HeBei, but also continuously radiates its innovation achievements to further regions. Based on this, this paper selects Beijing for empirical analysis.

\section{A. Combing Beijing Innovation Policy}

To assess the economic impact of the Beijing municipal science and technology innovation policy, the author of this paper combed the Beijing area during the period of 2006 to 2017 released by the Beijing science and technology innovation policy, the use of the Beijing municipal commission of science and technology website in Beijing science and technology policy platform, from 2006 to 2017 , the Beijing municipal science and technology and regulations document issued a total of 83, Beijing science and technology commission regulatory documents, 81 , Beijing municipal science and technology policy 178 other items, by sifting through remove duplicate degree is higher, and the failure of policy for a total of 47, eventually sort out the effective policy 295 science and technology innovation in Beijing, Classify the 295 policies that have been sorted out.

There are many classification methods for policies by domestic and foreign scholars. Bataille proposes policy features -- market distance research framework from an evolutionary perspective, and subdivides regional science and technology innovation policies into non-commercial policies, predictive policies, task-oriented policies and diffusion-oriented policies [7]. Kleinwoo-ithuis and Lankhuizen classify policy tools into authoritative, informational, fiscal and organizational types according to the different resources used by the government [8]. In-gram et al. divided the policy tools into four categories, i.e., persuasion type, command type, institutional change type and capacity building type, according to the policy objective [9]. Based on the research results of Zhang Yongan and Geng Zhe [10], this paper is divided into supply-push policies, demand-pull policies and environmental policies according to the role of science and technology innovation policies in innovation activities. According to the content analysis method, the description of the policy text is analyzed one by one, and the policy is classified according to the keywords of various types of policy description. We will code 295 policy, encoding the policy category ( 1 is the Beijing municipal science and technology and regulations documents / 2 normative documents / 3 for the Beijing municipal science and technology commission for the Beijing municipal science and technology policy) other supply-push policy, policy number, S/E/R environment demand-pull policy - order number, from the analysis of policies of supply driven, demand driven and environment type, the specific quantity distribution is shown in Fig. 1:

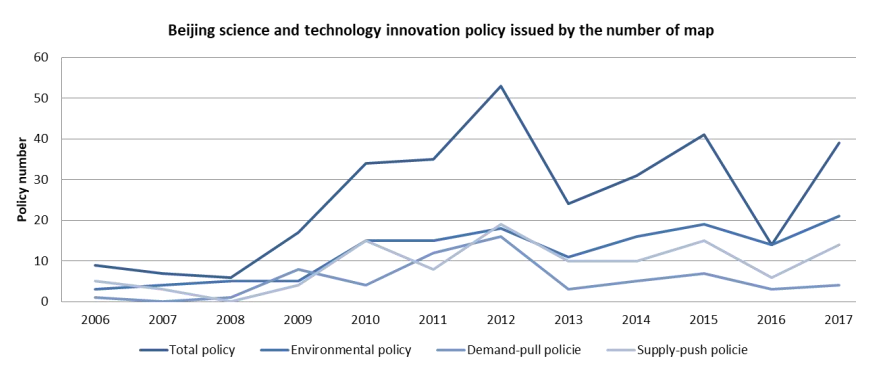

Fig. 1. Number distribution of science and technology innovation policies in Beijing.

From the point of total distribution, from 2006 to 2017, the Beijing municipal science and technology innovation policy release quantity volatility, present a tendency of increasing overall, 2008-2012 policy release quantity rise obviously, released in 2013 the number back, both in total and three kinds of policy, respectively, in 2016 is the least number of, this year not only less quantity, content and policy only covers the transformation of scientific and technological achievements and innovation platform demonstration project construction, covering range is limited; The number of policies issued in 2012 was relatively large, with the largest amount of policies, among which the number of other science and technology policies issued in Beijing was high and the policy coverage was wide. The number of science and technology innovation policies issued in 2017 rebounded, basically the same as that in 2012, and the distribution was uneven.

Seen from Fig. 1, the Beijing municipal science and technology innovation policy released three kinds of policy tools are involved, in accordance with the policy content of statistical data, three kinds of policy from the point of release quantity, the most number of environmental policy, accounted for $46 \%$, the second for supply policy, promoting type accounted for $34 \%$, accounted for the least for demand-pull policy, accounted for $20 \%$; Three kinds of policy by the year of release, increasing overall trends are present but there are large fluctuations, from the point of all kinds of policies issued amount, environmental policy every year the number of release is higher than other two kinds of policy, for all kinds of policies issued in 2012 years, all kinds of policy number has reached a peak, and the range is wide, for policy issued a trough in 2016 years, each kind of policy issued fewest, released in 2017 Numbers rebound trend, the surge in the number. From three kinds of policy content point of view, environmental policy is the most commonly used for the financial support, goal planning, tax incentives and regulatory, GongGeiXing policy 2006-2012 for more talents incentive, subsidies for research and development, and investment in science and technology, policy content in 2012-2017 for technical support, financing support, etc., more demand-pull policy content of government procurement, technology gradually transition to the demonstration project and foreign contracted.

Determination of evaluation index of the effect of Beijing science and technology innovation policy.

The indicators selected in this paper come from two aspects. First, through reading a large amount of relevant 
literature, in-depth analysis is made on relevant issues, and some classic indicators suitable for this study are selected. Second, through text mining of science and technology innovation policy information, the core of science and technology innovation policy is understood and grasped, and then the indicators are determined by further combining this research problem.

Explained variable -- revenue from new product sales. The sales revenue of new products is an important index to evaluate the effect of scientific and technological innovation policy. Therefore, this paper selects sales revenue of new products as the explained variable.

Throughout domestic and foreign studies, the choice of explanatory variables in this paper is to select different evaluation indexes according to the characteristics of three types of policies.

Demand-pull policies are policies formulated by the government from the perspective of increasing the demand for products and services to stimulate innovation activities and reduce the risk of scientific and technological innovation demands. According to the keywords mentioned in Table I the following indicators are mainly selected as explanatory variables:

A1 Number of patent applications accepted A2 Number of patent applications, A3 Technology market transaction contract amount, $\mathrm{A}_{4}$ Number of technical market contracts, $\mathrm{A}_{5}$ Scientific and technological progress award at provincial level or above, $\mathrm{A}_{6}$ Total output value of high-tech manufacturing, $A_{7}$ Total industrial output value, $A_{8}$ The total output value of high-tech industry accounts for the proportion of total output value of industry, $A_{9}$ Main business income of enterprises above the scale, $A_{10}$ Number of scientific papers, A11R\&D number of projects a total of 11 indicator.

Supply-Push policy is a policy formulated by the government for supporting factor supply. It includes the support of capital, talent, technology, knowledge, information and infrastructure. Therefore, supply policy is mainly reflected in the two categories of capital and talent. According to the key words mentioned, the following indicators are mainly selected as explanatory variables, $\mathrm{B}_{1}$ Industrial enterprises above the scale have the number of units of R\&D activities, $B_{2}$ Number of scientific and technical personnel, $\mathrm{B}_{3}$ Number of R\&D personnel, $\mathrm{B}_{4}$ The proportion of $R \& D$ personnel engaged in scientific and technological activities, $\mathrm{B}_{5}$ Total internal expenditure of RD funds, $\mathrm{B}_{6} \mathrm{R} \& \mathrm{D}$ expenditure accounts for the proportion of GDP, $B_{7}$ R\&D personnel equivalent full time, total seven indicators.

Environmental policy aims to improve the economic environment, legal environment and political environment needed for scientific and technological innovation. According to the keywords mentioned, the following indicators are mainly selected as explanatory variables, $\mathrm{C}_{1}$ Per capita GDP, $\mathrm{C}_{2}$ Industrial added value of enterprises above designated size, $\mathrm{C}_{3}$ Total industrial profits of enterprises above designated size, $\mathrm{C}_{4}$ Gross industrial output value of enterprises above designated size, $\mathrm{C}_{5}$ Secondary industry labor productivity, $\mathrm{C}_{6}$ GDP growth rate, $\mathrm{C}_{7}$ Full-scale labor productivity of industrial enterprises above designated size, a total of seven indicators.

\section{B. LASSO Algorithm Reduces Dimension Final Stage}

All data in this study are derived from public data such as China bureau of statistics website and Beijing bureau website. In order to eliminate the influence of price, exchange rate, unit and other factors on the variables, relevant data, such as GDP and industrial added value above the norm, were processed accordingly. The missing data were supplemented by Monte Carlo algorithm. In order to obtain better dimensionality reduction results, this study completed variable screening through LASSO algorithm, simplified data structure, and extracted low-dimensional sample data to reflect the overall data information.

Lasso method was first proposed by Tibshirani in 1996. By constructing a penalty function to get a refining model, the compression coefficient makes some coefficients of compression zero at the same time, and then the index can be simplified. At the same time of parameter estimation, variable selection is implemented.

Let's say I have $m$ independent variables $x_{1}, x_{2}, \cdots, x_{m}$, and dependent variable $y$, the linear model can be established as follows:

$$
y=\alpha+\beta_{1} x_{1}+\beta_{2} x_{2}+\cdots+\beta_{m} x_{m}+\varepsilon
$$

In the formula, $\alpha$ is the constant term, $\beta_{1}, \cdots, \beta_{m}$ is the regression coefficient, $\varepsilon$ stands for the random disturbance term.

Assuming that $\left(x_{i 1}, x_{i 2}, \cdots \cdots x_{i m} ; y_{i}\right)_{n}, i=1,2, \cdots \cdots, n$, this is $n$ sets of observations of the variable. Assume that the data has been centralized and standardized, $\sum_{i=1}^{n} y_{i}=0, \sum_{i=1}^{n} X_{i j}=0$, $\sum_{i=1}^{n} X_{i j}^{2}=1, j=1,2, \cdots, m, \beta=\left(\beta_{1}, \beta_{2}, \cdots \beta_{m}\right)^{T}$, the Lasso estimation of parameter a and beta in the formula is defined as:

$$
(\hat{\alpha}, \hat{\beta})=\arg \min \left\{\sum_{i=1}^{n}\left(y_{i}-\sum_{j=0}^{m} \beta_{j} x_{i j}\right)^{2}\right\}, \text { s.t. } \sum_{j=1}^{m}\left|\beta_{j}\right| \leq s
$$

In the formula, $s \geq 0$ is the penalty parameter, when $s<$ $s_{0}$, some regression coefficients will be reduced or tend to 0 or even equal to zero. At this time, the variables equal to zero will be deleted to achieve the purpose of variable selection.

On this basis, the following linear model is constructed:

$$
\begin{array}{r}
\beta_{1} \ln A_{1}+\beta_{2} \ln A_{2}+\cdots \cdots+\beta_{11} \ln A_{11}+\varepsilon \quad \alpha_{1}+ \\
\ln y=\alpha_{2}+\gamma_{1} \ln B_{1}+\gamma_{2} \ln B_{2}+\cdots \cdots+\gamma_{7} \ln B_{7}+\theta \\
\ln y=\alpha_{3}+\omega_{1} \ln C_{1}+\omega_{2} \ln C_{2}+\cdots \cdots+\omega_{7} \ln C_{7}+\sigma(4)
\end{array}
$$

In the formula, $\alpha_{1}, \alpha_{2}, \alpha_{3}$ are constant terms, $\beta_{1} \cdots \beta_{11}$, $\gamma_{1} \cdots \gamma_{7}, \omega_{1} \cdots \omega_{7}$ are the coefficients of each variable, $\varepsilon, \theta, \sigma$ are random perturbations, standardize and centralize the data before data analysis.

Lasso algorithm USES MATLAB software to calculate. According to AIC criterion, akichi information criterion, this paper chooses the best solution. 
Data processing of dimension reduction of lasso for demand-pull policy is shown in Table I:

TABLE I: Dimension Reduction Data of Demand-Pull Policies

\begin{tabular}{cccccccc}
\hline & 1 & 2 & 3 & $\ldots \ldots$ & $\ldots$ & 69 & 70 \\
\hline $\mathrm{A}_{1}$ & 0.005587 & 0.005563 & 0.005532 & $\ldots \ldots$ & $\ldots \ldots$ & 0 & 0 \\
$\mathrm{~A}_{2}$ & 0.005194 & 0.005059 & 0.004924 & $\ldots \ldots$ & $\ldots \ldots$ & 0 & 0 \\
& & & & & & & \\
$\mathrm{~A}_{3}$ & -0.00011 & -0.00011 & -0.00010 & $\ldots \ldots$ & $\ldots \ldots$ & 0 & 0 \\
$\mathrm{~A}_{4}$ & -0.00451 & -0.00449 & -0.00447 & $\ldots \ldots$ & $\ldots \ldots$ & -6.282723 & -1.315502 \\
$\mathrm{~A}_{5}$ & $-5.14 \mathrm{E}-06$ & $-5.13 \mathrm{E}-06$ & $-5.13 \mathrm{E}-06$ & $\ldots \ldots$ & $\ldots \ldots$ & $-2.092 \mathrm{e}-07$ & $-4.224 \mathrm{e}-08$ \\
$\mathrm{~A}_{6}$ & $6.59 \mathrm{E}-05$ & $6.62 \mathrm{E}-05$ & $6.65 \mathrm{E}-05$ & $\ldots \ldots$ & $\ldots \ldots$ & $4.890 \mathrm{e}-05$ & $4.758 \mathrm{e}-05$ \\
$\mathrm{~A}_{7}$ & 0.001221 & 0.001214 & 0.001206 & $\ldots \ldots$ & $\ldots \ldots$ & $3.8869 \mathrm{e}-05$ & $3.2456 \mathrm{e}-05$ \\
$\mathrm{~A}_{8}$ & $9.10 \mathrm{E}-09$ & $9.01 \mathrm{E}-09$ & $8.92 \mathrm{E}-09$ & $\ldots \ldots$ & $\ldots \ldots$ & 0 & 0 \\
$\mathrm{~A}_{9}$ & -0.081 & -0.0882 & -0.0938 & $\ldots \ldots$ & $\ldots \ldots$ & 0 & 0 \\
$\mathrm{~A}_{10}$ & -0.00072 & -0.00071 & -0.00069 & $\ldots \ldots$ & $\ldots \ldots$ & $-3.039 \mathrm{e}-07$ & 0 \\
$\mathrm{~A}_{11}$ & 0.00097 & 0.000962 & 0.000951 & $\ldots \ldots$ & $\ldots \ldots$ & 0 & 0 \\
\hline
\end{tabular}

Results the first 70 steps were selected. At the 70 steps, AIC value was the smallest and the result was the best. Based on the above data analysis, $A_{1}, A_{2}, A_{3}, A_{8}, A_{9}, A_{10}, A_{11}$ the LASSO algorithm processing coefficient is zero, so the final extract characteristic index for $\mathrm{A}_{4}$ technology market clinch a deal the contract number (item), $\mathrm{A}_{5}$ and provincial-level progress prize in science and technology (item), $\mathrm{A}_{6}$ high-tech manufacturing output (one hundred million yuan), the $A_{7}$ gross value of industrial output (one hundred million yuan) four variables.

Data results of dimension reduction of lasso for supply-push policies are shown in Table II:

TABLE II: SUPPLy-PUSH POLICY Dimension REDUCTION DATA

\begin{tabular}{llllllll}
\hline & 1 & 2 & 3 & $\ldots \ldots$ & $\ldots \ldots$ & 69 & 70 \\
\hline $\mathrm{B}_{1}$ & -0.00019 & -0.00019 & -0.00019 & $\ldots \ldots$ & $\ldots \ldots$ & $-1.3 \mathrm{E}-05$ & $-1.4 \mathrm{E}-05$ \\
$\mathrm{~B}_{2}$ & 0.029767 & 0.029921 & 0.030061 & $\ldots \ldots$ & $\ldots \ldots$ & 0 & 0 \\
$\mathrm{~B}_{3}$ & 0.009521 & 0.009509 & 0.009494 & $\ldots \ldots$ & $\ldots \ldots$ & 0.005140 & 0.004965 \\
$\mathrm{~B}_{4}$ & $2.78 \mathrm{E}-09$ & $2.77 \mathrm{E}-09$ & $2.76 \mathrm{E}-09$ & $\ldots \ldots$ & $\ldots \ldots$ & 0 & 0 \\
$\mathrm{~B}_{5}$ & $9.71 \mathrm{E}-01$ & $9.53 \mathrm{E}-01$ & $9.35 \mathrm{E}-01$ & $\ldots \ldots$ & $\ldots \ldots$ & 0 & 0 \\
$\mathrm{~B}_{6}$ & $-1.22 \mathrm{E}-07$ & $-1.21 \mathrm{E}-07$ & $-1.21 \mathrm{E}-07$ & $\ldots \ldots$ & $\ldots \ldots$ & $-7.58 \mathrm{E}-0$ & $-6.13 \mathrm{E}-0$ \\
$\mathrm{~B}_{7}$ & -0.00019 & -0.00019 & -0.00019 & $\ldots \ldots$ & $\ldots \ldots$ & 0.000406 & 0.00039 \\
\hline
\end{tabular}

The extracted characteristics of supply-driven policy are four variables: number of RD activity units, number of B3RD personnel (people), proportion of B6RD expenditure in GDP, and conversion of B7RD personnel into full time equivalent (person year).

The dimensionality reduction data of environmental policy lasso are shown in Table III:

TABLE IV: DimENSION REDUCTION DATA OF ENVIRONMENTAL POLICIES

\begin{tabular}{llllllll}
\hline & 1 & 2 & 3 & $\ldots \ldots$ & $\ldots \ldots$ & 69 & 70 \\
\hline $\mathrm{C}_{1}$ & $-4.1 \mathrm{E}-03$ & $-4.1 \mathrm{E}-03$ & -0.0040 & $\ldots \ldots$ & $\ldots \ldots$ & 0 & 0 \\
$\mathrm{C}_{2}$ & -0.00021 & -0.00020 & -0.00020 & $\ldots \ldots$ & $\ldots \ldots$ & 0 & 0 \\
$\mathrm{C}_{3}$ & 0.16081 & 0.15642 & 0.15195 & $\ldots \ldots$ & $\ldots \ldots$ & 0 & 0 \\
$\mathrm{C}_{4}$ & $5.1 \mathrm{E}-04$ & $5.0 \mathrm{E}-04$ & $4.0 \mathrm{E}-04$ & $\ldots \ldots$ & $\ldots \ldots$ & 0 & 0 \\
$\mathrm{C}_{5}$ & $2.6 \mathrm{E}-03$ & $2.6 \mathrm{E}-03$ & $2.6 \mathrm{E}-03$ & $\ldots \ldots$ & $\ldots \ldots$ & 0 & 0 \\
$\mathrm{C}_{6}$ & $1.2 \mathrm{E}-07$ & $1.2 \mathrm{E}-07$ & $1.3 \mathrm{E}-07$ & $\ldots \ldots$ & $\ldots \ldots$ & $6.26 \mathrm{E}-08$ & $5.3 \mathrm{E}-08$ \\
$\mathrm{C}_{7}$ & 0.03233 & 0.03197 & 0.03161 & $\ldots \ldots$ & $\ldots \ldots$ & 0.011272 & 0.01097 \\
\hline
\end{tabular}

Environmental policies are characterized by $\mathrm{C}_{6} \mathrm{GDP}$ growth rate and full labor productivity of industrial enterprises above $\mathrm{C}_{7}$ scale.

The results of the first 70 steps were selected according to the data processing results of lasso dimension reduction policy. At step 70, the AIC value was minimum and the results were optimal. Based on the above data analysis, the selected indexes after dimension reduction of Lasso algorithm are shown in Fig. 2.

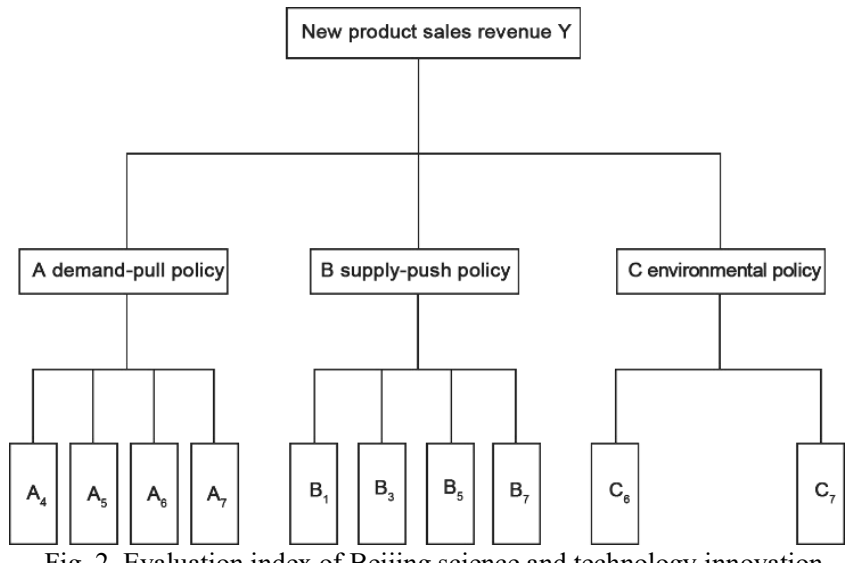

Fig. 2. Evaluation index of Beijing science and technology innovation policies.

\section{DISCUSSION}

According to the foregoing, this study adopts the three-layer forward model, namely the input layer, hidden layer and output layer. According to the above data processing results, the input variable is $\mathrm{x}_{1}=\mathrm{A}_{4}, \mathrm{x}_{2}=\mathrm{A}_{5}, \mathrm{x}_{3}=\mathrm{A}_{6}$, $\mathrm{x}_{4}=\mathrm{A}_{7}, \mathrm{x}_{5}=\mathrm{B}_{1}, \mathrm{x}_{6}=\mathrm{B}_{3}, \mathrm{x}_{7}=\mathrm{B}_{5}, \mathrm{x}_{8}=\mathrm{B}_{7}, \mathrm{x}_{9}=\mathrm{C}_{6}, \mathrm{x}_{10}=\mathrm{C}_{7}$, input layer node number $\mathrm{n}=10$, according to the empirical data, the number of hidden layer nodes is set to $r=10$, the output layer node number for the $\mathrm{y}$ new product sales income, namely, $m=1$, according to the need of the model and the need of software, the error precision is set to $10^{-3}$. In this model, Logsig function is selected as the transfer function of the input layer and hidden layer, and Purelin function is selected as the transfer function of the output layer. The training function chosen in this study is Traingdx optimization because of its high efficiency and high accuracy.

BP neural network algorithm is suitable for the study of highly nonlinear relationship, and it can extract knowledge from data autonomously. BP neural network is a kind of multi-layer feed-forward neural network. This paper USES three layers of neural network, including input layer, hidden layer and output layer. Data from the input layer into the hidden layer layer by layer processing, until the output layer. The state of neurons in each layer only affects the state of neurons in the next layer. If the expected output is not obtained in the output layer, the back propagation is carried out, and the weights and thresholds of the network are adjusted according to the prediction error, so that the predicted output of BP neural network keeps approaching the expected output. Neural network weights and thresholds are modified based on gradient descent.

The BP neural network model construction figure is shown below (see it in Fig. 3).

For enterprises, the sales revenue of new products is due to the combined effect of demand-driven, supply-driven and environmental policies. Therefore, relevant data of Beijing 
from 2006 to 2017 were input, and the neural network model was constructed with MATLAB and the model training was shown in Fig. 4.

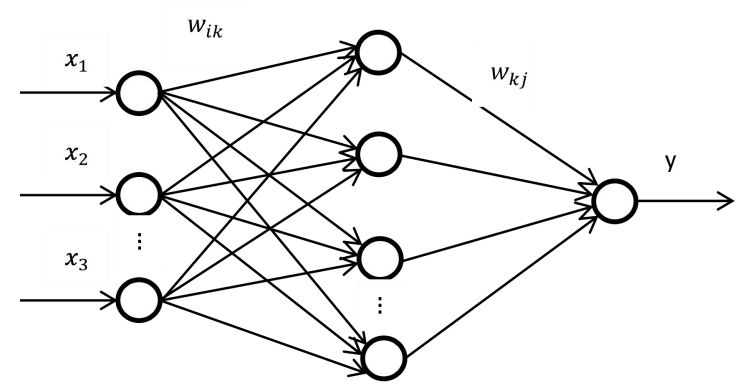

Fig. 3. BP neural network construction diagram.

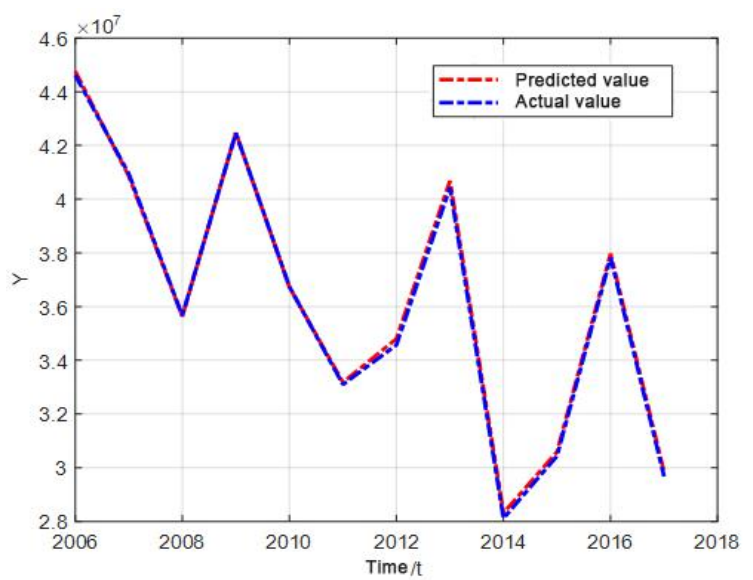

Fig. 4. Forecast output of Beijing science and technology innovation policy effect neural network effect.

In Fig. 4, the blue line and red line are almost completely fitted, and the network prediction error is within the control range, and the fitting effect is good. Then the indicators of demand-pull policies $\mathrm{x}_{1}=\mathrm{A}_{4}, \quad \mathrm{x}_{2}=\mathrm{A}_{5}, \quad \mathrm{x}_{3}=\mathrm{A}_{6}, \quad \mathrm{x}_{4}=\mathrm{A}_{7}$, supply-push policies $\mathrm{x}_{5}=\mathrm{B}_{1}, \mathrm{x}_{6}=\mathrm{B}_{3}, \mathrm{x}_{7}=\mathrm{B}_{5}, \mathrm{x}_{8}=\mathrm{B}_{7}$ and environmental policies $\mathrm{x}_{9}=\mathrm{C}_{6}, \mathrm{x}_{10}=\mathrm{C}_{7}$ are brought into the neural network model for calculation, to calculate the $y_{1}, y_{2}$, $y_{3}$, therefore, the effect of demand-pull policy can be expressed as follows $\mathrm{z}_{1}=y_{1} / y$, supply-push policy effect can be expressed as $z_{2}=y_{2} / y$, the effect of environmental policy is expressed as $z_{3}=y_{3} / y$.

Fig. 5 is the specific data of the policy effect of the three types of policies.

It can be seen from Fig. 5 that the environmental policy effect of Beijing's science and technology innovation policies is decreasing year by year, the effect of supply-driven policies is increasing year by year, and the effect of demand-driven policies varies little, showing a downward trend on the whole.

The effects of supply-driven policies have increased significantly, which is directly related to the changes in policy contents and the adjustment of policy priorities over the years. The policy content has gradually shifted from talent funding and scientific research investment to technical support and financing support. The direct policy of scientific research investment subsidy has achieved obvious effects, while the policy effect of technical support and financing support has been slow to emerge. Therefore, the effect of supply-type policy has fallen down since 2016 .
The effect of demand-driven policies is stable. In Beijing's science and technology innovation policies, the change trend of the quantity of demand-type policies is basically the same as the trend of effect measurement. Both the quantity and the effect of policies are two trough points in 2007 and 2016.The policy contents of 2008-2012 mainly include government procurement and technology identification, and the policy effect appears relatively fast. After 2012, the policy focus is on demonstration projects, and the effect appears relatively slow, so the policy effect decreases in the short term.

The effect of environmental policies is significantly reduced. The number of environmental policies of Beijing's science and technology innovation is increasing year by year, but the effect of policies is decreasing year by year, indicating that the construction of Beijing's innovation environment needs to be strengthened at present. In recent years, the environmental policies launched by Beijing are mainly financial support, target planning, tax preference, and regulations and control. The mid-term tax preference policies have achieved remarkable results, but the policy effects such as target planning and regulations and control have been delayed for a long time.

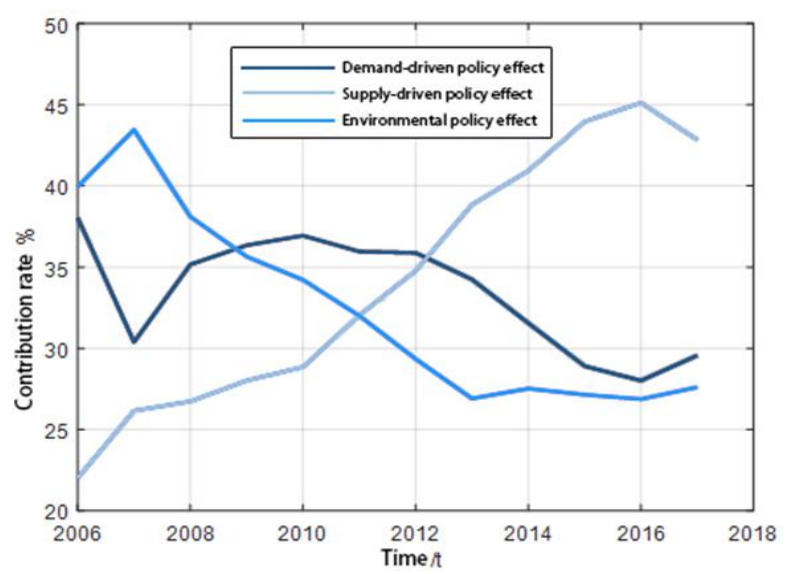

Fig. 5. Beijing science and technology innovation policy classification policy effect calculation chart.

\section{CONCLUSION}

There are many scholars and methods to study the effects of policies, but the analysis combined with big data algorithm is relatively rare. This paper USES the data of Beijing from 2006 to 2017 to make up for this deficiency. This paper mainly draws the following two conclusions. One is to strengthen the implementation of environmental policies, which are the cornerstone of innovation activities. According to the existing data analysis, the cultivation of innovation environment in Beijing is not perfect. First of all, we should give full play to the geographical advantages of Beijing, closely integrate relevant environmental policies issued by the state, earnestly implement relevant laws and regulations of environmental policies, and lay out a good legal environment in all links of innovation activities. Secondly, the speed of information transmission, information exchange and sharing, and the flow of information among the innovative enterprises should be strengthened. Strengthen the guiding role of the government in the implementation of environmental policies, strengthen supervision, focus on the implementation of key projects, and strengthen the 
demonstration construction of Zhongguancun, so as to ensure the steady progress of scientific and technological innovation activities. The second is to increase the quantity of supply-driven policies. The lag period of supply-driven policies is short and the effect is significant. Therefore, we can consider increasing the quantity of supply-driven policies in the future policy making process.

This study also has certain limitations. Firstly, this paper studies the effects of scientific and technological innovation policies from the perspective of time dimension; secondly, it can explore the effects of policies from the perspective of enterprise subject and spatial dimension; secondly, the evaluation indexes of policy effects can be improved.

\section{CONFLICT OF INTEREST}

The authors declare no conflict of interest.

\section{AUTHOR CONTRIBUTIONS}

Guan Yongjuan contributed the central idea, analysed most of the data, and wrote the initial draft of the paper. Zhang Yongan contributed to refining the ideas, carrying out additional analyses and finalizing this paper; all authors had approved the final version.

\section{ACKNOWLEDGMENT}

I would like to thank my mentor professor Zhang Yongan and the conference technical committee for their valuable advice on this research. These valuable opinions helped me greatly improve the quality of this manuscript.

\section{REFERENCES}

[1] H. B. Gui, "Spatial measurement evaluation of government procurement policies to promote technological innovation," Scientific Research Management, vol. 9, pp. 161-168, 2017.

[2] L. Chen and W. H. Yang, "Allocation mechanism and policy effect of R\&D tax deduction," Scientific Research Management, vol. 7, pp. 38-45, 2017.

[3] H. Z. Liu, "Policy performance study of carbon tax policy on technological innovation behavior of industrial enterprises in China," Industrial Technology Economy, vol. 9, pp. 73-78, 2017.
[4] M. H. Zhu, "Effect analysis of technological innovation policies in China's automobile industry," Scientific Research Management, vol. 7, pp. 27-38, 2017.

[5] F. M. Li, Y. L. Liu et al., "Impact of industrial policies on innovation and economic performance of China's photovoltaic enterprises," Science of Science and Management of S.\&T., vol. 11, pp. 49-63, 2017.

[6] Z. B. Li, B. Liang et al., "Effect evaluation of innovation policies on high-tech enterprises," Innovation and Entrepreneurship, pp. 42-48.

[7] C. Bataille, "Hybrid modeling of energy-environment policies: Reconciling bottom-up and top-down," Special Issue of The Energy Journal, pp. 93-112, 2006

[8] K. Lankhuizenm, "A system failure framework for innovation policy design," Technovation, vol. 25, no. 6, pp. 609-619, 2005.

[9] Ingrams, "Behavioral assumption of policy tools," The Journal of Politics, vol. 52, pp. 510-529, 1990.

[10] Y. G. Zhang, Z. Geng, and Y. N. Wang, "Systematic classification of regional science and technology innovation policies in China - based on research of Zhong Guancun data," Chinese Journal of Systems Science, vol. 5, pp. 92-96, 2016.

Copyright (C) 2020 by the authors. This is an open access article distributed under the Creative Commons Attribution License which permits unrestricted use, distribution, and reproduction in any medium, provided the original work is properly cited (CC BY 4.0).

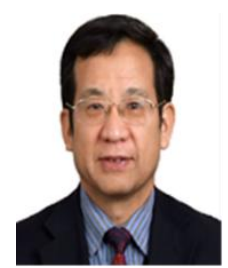

Yongan Zhang was born in Xianyang, Shaanxi province. He graduated from Northwestern Polytechnical University in 1982 with a bachelor of science degree. He graduated from the School of Management of Xi'an Jiaotong University in 1998 and obtained a doctor's degree in management. He was hired as a doctoral supervisor in 2004, his research interests include complexity of economic and management systems, policy management and simulation.

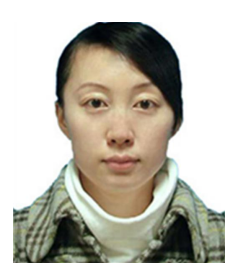

Yongjuan Guan was born in Suihua in Heilongjiang province. She graduated from Harbin University of Science and Technology in 2004, she got a bachelor's degree in engineering in 2009. She graduated from Harbin University of Science and Technology, College of Economics and Management, and get a master's degree in Beijing University of Technology in 2017 with majoring in management science and engineering. Her research area is in innovation policy, management theory and method of research direction. 